\title{
Temperature and Reactive Current Distributions in Microtubular Solid Oxide Electrolysis Cells
}

\author{
T. Mizusawa ${ }^{\mathrm{a}}, \mathrm{T}$. Araki $^{\mathrm{b}}$ and M. Mori ${ }^{\mathrm{c}}$
}

${ }^{a}$ Department of Systems Integration, Graduate School of Engineering, Yokohama National University, 79.5 Tokiwadai, Hodogaya, Yokohama, Kanagawa 240-8501 Japan

${ }^{b}$ Faculty of Engineering, Yokohama National University, 79-5 Tokiwadai, Hodogaya, Yokohama, Kanagawa 240-8501 Japan

${ }^{c}$ Central Research Institute of the Electric Power Industry, 2-6-1 Nagasaka, Yokosuka, Kanagawa 240-2196 Japan

$\begin{array}{ll}\text { Corresponding author: } & \text { Tatsuya Mizusawa } \\ \text { Telephone/Fax: } & +81-45-339-3906 \\ \text { E-mail address: } & \text { mizusawa-tatsuya-zx@ynu.jp }\end{array}$

\begin{abstract}
A two-dimensional tubular model of a cathode supportedmicrotubular solid oxide electrolysis cell (SOEC) was developed in order to investigate the temperature distribution within the cell during high-temperature steam electrolysis. High-temperature steam electrolysis using SOECs allows for highly efficient hydrogen generation, because the heat from the overpotential can be recycled in the form of a heat source for the electrolysis reaction. However, to improve the durability and strength of the components, an understanding of the temperature distribution of the cell is essential, because heat absorption during electrolysis reaction leads to complex temperature distributions. The current density-voltage curves obtained using the above-mentioned model were in good agreement with the experimental ones. The calculated and measured temperature distributions indicated that the distribution in microtubular SOECs is a nonuniform one and suggested that the current-collecting positions strongly affect the temperature and reaction distributions under the conditions used herein.
\end{abstract}

\section{Introduction}

In recent years, energy from natural energy sources such as solar and wind power has been added to the electric grid, as it is clean and renewable. However, both wind and solar power exhibit instability with respect to changes in the weather. As the proportion of these types of energies increases steadily, adequate controls will become necessary to stabilize the grid. Hydrogen generation systems that employ electrolysis techniques are expected to be

(C) 2016. This manuscript version is made available under the Elsevier user license

http://www.elsevier.com/open-access/userlicense/1.0/ 
used as large-capacity power storage facilities with the ability to stabilize the electrical power supply. In particular, high-temperature steam electrolysis performed using solid oxide electrolysis cells (SOECs) can generate hydrogen with high efficiency [1-3], because the heat from the overpotential can be recycled in the form of a heat source for the electrolysis reaction. In addition, owing to the endothermic nature of the reaction, increases in the temperature of the SOEC are prevented. However,understanding temperature distributions of the microtubular SOEC is essential to design the cell that have high durability and reliability while the measurements of electrolysis performances of SOECs were reported[4-6]. M. Laguna-Bercero, et al.[4] measured electrochemical performance of SOECs with scandea stabilized zirconia. S. D. Ebbesen, et al.[5] and C. Stoots, et al.[6] measuredthe long term hydrogen production performance by theelectrolysis using SOECs.

Although the temperature distributions in planar SOECs have been investigated previously [7-11], there have been few reports on the temperature distributions in microtubular SOECs. The temperature distributions in microtubular SOECs are probably more complex than those in planar SOECs, since nonuniform reaction distributions cannot be predicted easily, owing to the difficulties associated with current collecting, in determining the concentration and flow direction of the reaction gases, and with selecting the proper insulation method. Further, investigating these distributions by experimental methods alone is difficult, given the thinness of the microtubular SOEC components and their extremely high operating temperatures $(\sim 900-1200 \mathrm{~K})$. Therefore, in order to understand these complicated phenomena, both experimental and numerical analyses are necessary.

A number of numerical models have been developed for solid oxide fuel cells (SOFCs), including a two-dimensional microporous model of a planar SOFC [8-14]. Because of the similarity of the phenomena that occur in SOFCs and SOECs, these reports serve as useful references for understanding the internal states of SOECs. However, the effects of the entropy changes are different for the reactions involved in electric power generation and electrolysis. In the case of electric power generation, an entropy change results in heat generation, whereas for electrolysis, it results in heat absorption. Therefore, the thermal-transport phenomena in SOECs will be more complex than those in SOFCs. As a result, SOFC models cannot be used directly to simulate SOECs.

Several models of planar SOECs have been described. Ni et al. $[1,15]$ developed a one-dimensional SOEC model to investigate the effects of the reactant concentration and microporous design on the electrochemical performance of SOECs. However, this model did not account for the heat transport phenomena. Njdozefon et al. [16] determined the current-temperature characteristics of an SOEC experimentally, in addition to performing one-dimensional calculations. A comparison of the experimental and numerical results suggested that temperature 
considerations were important when determining the electrochemical performance. Two- and three-dimensional thermal models that take into account the temperature and reactive current distributions and the reactant concentrations have also been reported [7-11]. Herring et al. [7] calculated the temperature and current density profiles of a single planar SOEC using the three-dimensional FLUENT model and measured the potential-current characteristics as well as the local temperatures of a 10-cell planar solid oxide electrolysis stack. On the basis of the obtained computational and experimental results, they discussed the effects of heat transfer, reaction cooling/heating, and changes in the local gas composition. Ni [8] reported a two-dimensional numerical model for coelectrolysis performed using a planar SOEC and discussed the effects of the inlet gas composition and inlet temperatures. Udagawa et al. $[9,10]$ described steady and unsteady states one-dimensional numerical models of a cathode (nickel + yttria stabilized zirconia: $\mathrm{Ni}+$ YSZ) supported intermediate-temperature SOEC stack and calculated the electrochemical performance of the device at various current densities and temperatures. Hikosaka et al. [11] predicted the electrochemical performance of a planar SOEC using numerical modeling and reported the energy efficiency of hydrogen generation using a model SOEC system. In terms of electrochemical performance, the average current density-potential characteristics of isothermal and nonisothermal models are nearly the same under the assumed conditions. Further, the energy efficiency during electrolysis can be as high as $122 \%$ when the heat required is supplied from outside the system (for example, by sunlight) [11]. However, these planar SOEC models cannot be used directly to simulate tubular SOECs because the current collectors in these models are placed across the cells [7-11]. Although tubular SOECs exhibit high thermal stress resistance because of their cylindrical form, they also exhibit high electronic resistance along the axis direction because of asymmetrical current collection. The asymmetrical positions of the current collectors and the large electronic resistance along the axis direction cause the temperature and reactive current distributions to be nonuniform. In addition, in this study, we often found that the microtubular SOEC broke during high-temperature steam electrolysis and that the breaking point was located in the non-active area, as shown in Fig. 1(b). If the breakage were caused by a change in the temperature or a temperature gradient, a numerical analysis of the microtubular SOEC that included only the active area would be inadequate for evaluating the effect on mechanical strength.

In this study, a numerical model of a cathode supported microtubular SOEC was developed in order to elucidate the temperature distribution within these devices. The model takes into account heat, mass, and charge transport and the related chemical reactions. The calculated average current density-voltage $(i-V)$ characteristics, average current density-change in temperature $(i-\Delta T)$ characteristics, and the temperature distributions at the surface of the 
SOEC were compared with the measuredones. The calculated $i-V$ curves, $i-\Delta T$ curves, and temperature distributions were in good agreement with those obtained experimentally. The calculated temperature distribution indicated that the temperature distribution in microtubular SOECs is nonuniform and that the positions of the current collectors strongly affect the temperature and reaction distributions.

\section{Numerical model}

Fig. 1 shows a cathode supported microtubular SOEC. The microporous cathode consisted of a mixture of nickel and $\left(\mathrm{ZrO}_{2}\right)_{0.92}\left(\mathrm{Y}_{2} \mathrm{O}_{3}\right)_{0.08}$ (YSZ); the electrolyte is $\mathrm{YSZ}$. The microporous anode was made of a mixture of $\mathrm{La}_{0.8} \mathrm{Sr}_{0.2} \mathrm{MnO}_{3}$ (LSM) and YSZ. The constitution and shape of the cell are shown in Fig. 1(a). The cell length was approximately $50 \mathrm{~mm}$, with the outer diameter being approximately $2 \mathrm{~mm}$.

The overpotential and temperature change characteristics of the microtubular SOEC were determined as functions of the current density. A schematic of the numerical model of the microtubular SOEC is shown in Fig. 1(c); the model is a steady-state, tubular, and two-dimensional one and can explain the phenomena occurring within a microtubular SOEC because a cylinder has axial symmetry. The geometric and physical properties of the microtubular SOEC are listed in Tables 1 and 2, respectively.

Table 1 Geometric parameters of the microtubular SOEC model

\begin{tabular}{lccrr}
\hline Parameter & LSM + YSZ & YSZ & Ni + YSZ & Unit \\
\hline Thickness & 0.02 & 0.02 & 0.20 & {$[\mathrm{~mm}]$} \\
Length & 30 & 30 & 50 & {$[\mathrm{~mm}]$} \\
Porosity $\left(\varepsilon_{\mathrm{p}}\right)$ & 0.5 & - & 0.4 & {$[-]$} \\
Electronic tortuosity $\left(\xi_{\mathrm{e}-}\right)$ & 1.00 & - & 3.17 & {$[-]$} \\
Ionic tortuosity $\left(\xi_{\text {ion }}\right)$ & 1.00 & 1.00 & 3.00 & {$[-]$} \\
YSZ volumetric fraction $(\phi)$ & 0.30 & 1.00 & 0.55 & {$[-]$} \\
\hline
\end{tabular}

Table 2 Physical parameters of the materials used in the SOEC

\begin{tabular}{lcc}
\hline Material & Thermal conductivity, $k^{\circ}\left[\mathrm{Wm}^{-1} \mathrm{~K}^{-1}\right][13]$ & Conductivity, $\sigma^{\circ}\left[\mathrm{Sm}^{-1}\right][12,17,18]$ \\
\hline LSM & 9.6 & $\sigma_{e-}^{\circ}=\frac{8.855 \times 10^{7}}{T} \exp \left(-\frac{1082.5}{T}\right)$ \\
& 2.7 & $\sigma_{\text {ion }}^{\circ}=3.34 \times 10^{4} \exp \left(-\frac{10300}{T}\right)$ \\
YSZ & - & $\sigma_{e-}^{\circ}=3.27 \times 10^{6}-1065.3 T$ \\
Ni & 6.23 & - \\
Ni+YSZ & & \\
\hline
\end{tabular}




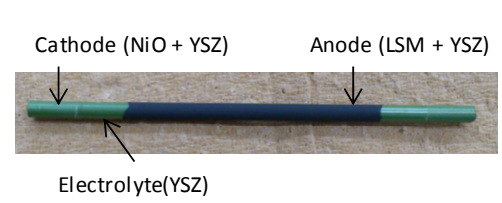

(a)

Gas seal (Ceramabond 552)

(b)

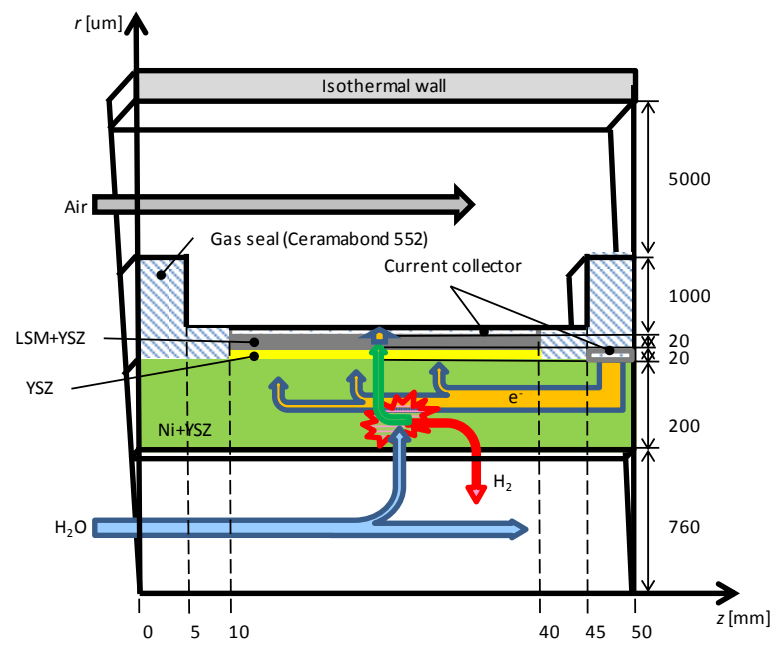

(c)

Fig. 1. (a) A cathode-supported microtubular SOEC, (b) a crack that formed in the SOEC during the measurements, and (c) schematic of the numerical model of the SOEC.

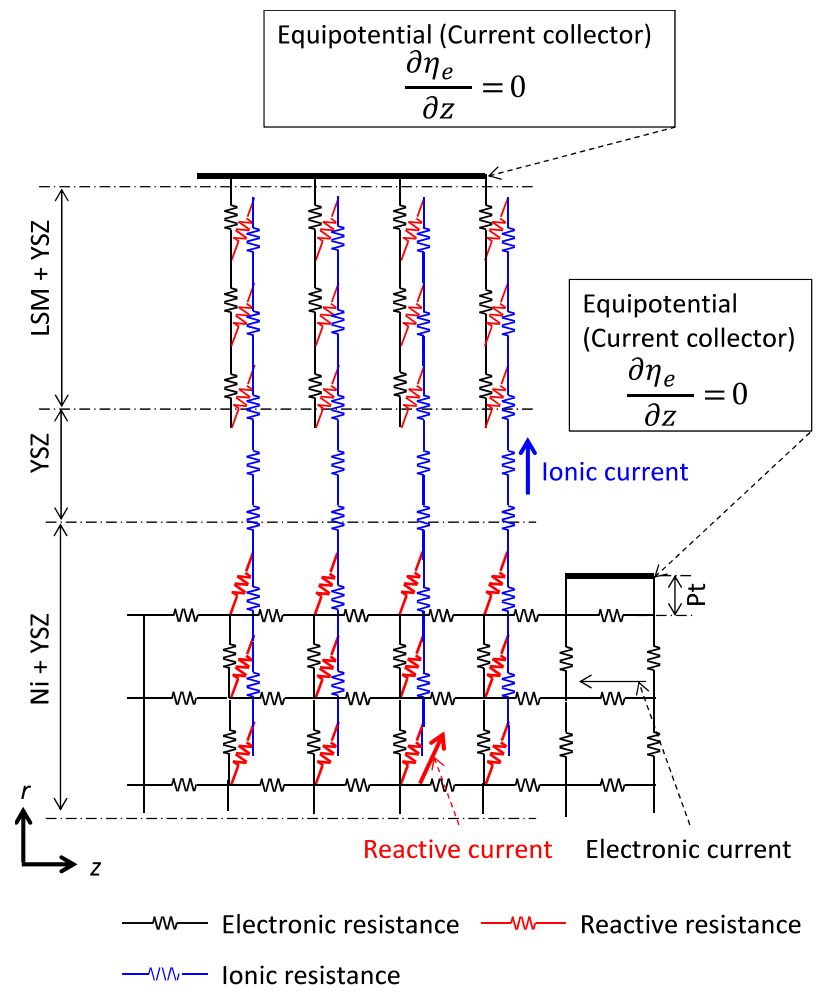

Fig. 2. An equivalent circuit model for the overpotentials in the microtubular SOEC. 


\subsection{Charge Transport}

An equivalent circuit of the microtubular SOEC is shown in Fig. 2. In this study, we assumed that the electrons and ions were transported only in the $r$-direction, as shown in Fig. 1(c) (the exception were the electrons in the $\mathrm{Ni}$

+ YSZ electrode), because of the thinness of the components. The electronic and ionic charge balance equations for the anode were

$$
\begin{aligned}
& 0=\nabla \cdot\left(\sigma_{\mathrm{e}-}^{\text {eff }} \nabla \eta_{e-}\right)+i_{\mathrm{v}} \\
& 0=\nabla \cdot\left(\sigma_{\text {ion }}^{\text {eff }} \nabla \eta_{\text {ion }}\right)-i_{\mathrm{v}},
\end{aligned}
$$

and those for the cathode were

$$
\begin{aligned}
& 0=\nabla \cdot\left(\sigma_{\mathrm{e}-}^{\text {eff }} \nabla \eta_{\mathrm{e}-}\right)-i_{\mathrm{v}} \\
& 0=\nabla \cdot\left(\sigma_{\text {ion }}^{\text {eff }} \nabla \eta_{\text {ion }}\right)+i_{\mathrm{v}}
\end{aligned}
$$

The ionic charge balance in the electrolyte was expressed as

$$
0=\nabla \cdot\left(\sigma_{\text {ion }}^{0} \nabla \eta_{\text {ion }}\right)
$$

where $\sigma_{\mathrm{e}-}^{\text {eff }}$ is the effective conductivity $\left[\mathrm{S} \mathrm{m}^{-1}\right], \eta$ is the overpotential [V], and $i_{\mathrm{v}}$ is the reactive current density per unit volume $\left[\mathrm{A} \mathrm{m}^{3}\right]$. The subscripts ion and $\mathrm{e}-$ denote the ionic and electronic variables, respectively. In this study, the charge balances were calculated from the overpotential. The ion overpotential was determined as

$$
\eta_{\text {ion }}=\phi_{\text {ion }}-\phi_{\text {ion }}^{0}
$$

The electron overpotentials of the anode and cathode were determined as

$$
\begin{aligned}
& \eta_{\mathrm{e}-\mathrm{a}}=\phi_{\mathrm{e}-a}-\phi_{\mathrm{e}-a}^{0} \\
& \eta_{\mathrm{e}-\mathrm{c}}=\phi_{\mathrm{e}-c}-\phi_{e-c}^{0} .
\end{aligned}
$$

where $\phi_{\mathrm{e}-}$ is the electron potential, and $\phi_{\mathrm{ion}}$ is the ion potential. The subscripts a and c represent the anode and cathode, respectively. The subscript 0 represents the equilibrium condition at $\mathrm{z}=0[\mathrm{~mm}]$ and the operating 
temperature. The change in the equilibrium electron potentials, which include the Nernst potential, was determined as

$$
\phi_{\mathrm{e}-a}^{0}-\phi_{\mathrm{e}-c}^{0}=\frac{\Delta \mathrm{G}_{\mathrm{r}}}{n F}+\frac{R T}{n F} \ln \left(\frac{P_{H_{2}}^{0} P_{O_{2}}^{0}}{P_{H_{2} O}^{0}}\right) .
$$

The effective conductivities were given by

$$
\begin{aligned}
& \sigma_{\mathrm{e}-}^{\mathrm{eff}}=\frac{\left(1-\varepsilon_{\mathrm{p}}\right)(1-\varphi)}{\xi_{\mathrm{e}-}} \sigma_{\mathrm{e}-}^{\circ} \\
& \sigma_{\text {ion }}^{\mathrm{eff}}=\frac{\left(1-\varepsilon_{\mathrm{p}}\right) \varphi}{\xi_{\text {ion }}} \sigma_{\text {ion }}^{\circ}
\end{aligned}
$$

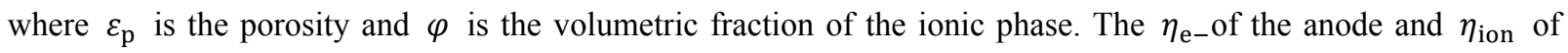
the cathode were determined as follows:

$$
\eta_{\mathrm{e}-}=\eta_{\mathrm{ion}}+\eta_{\mathrm{r}}
$$

and

$$
\eta_{\text {ion }}=\eta_{\mathrm{e}-}+\eta_{\mathrm{r}}
$$

The reactive overpotential, $\eta_{\mathrm{r}}$, was calculated using the Butler-Volmer-type equation, which was corrected using the activities of the reactants:

$$
\begin{aligned}
& \eta_{\mathrm{r}, \mathrm{c}}=\frac{R T}{n \alpha F} \sinh ^{-1}\left(\frac{i_{\mathrm{v}}}{2 i_{\mathrm{o}}}\right)+\frac{R T}{n F} \ln \left(\frac{p_{\mathrm{H}_{2}}}{p_{\mathrm{H}_{2}^{0}}} \frac{p_{\mathrm{H}_{2} \mathrm{O}}^{0} \mathrm{O}}{p_{\mathrm{H}_{2} \mathrm{O}}}\right) \\
& \eta_{\mathrm{r}, \mathrm{a}}=\frac{R T}{n \alpha F} \sinh ^{-1}\left(\frac{i_{\mathrm{v}}}{2 i_{\mathrm{o}}}\right)+\frac{R T}{n F} \ln \left(\frac{p_{\mathrm{O}_{2}}}{p_{\mathrm{O}_{2}}^{0}}\right) \\
& \mathrm{i}_{0}=\gamma_{\mathrm{c}} T \exp \left(-\frac{\Delta E_{c}}{R T}\right) \\
& \mathrm{i}_{0}=\gamma_{\mathrm{a}} T \exp \left(-\frac{\Delta E_{a}}{R T}\right)
\end{aligned}
$$


where $R$ is the gas constant $\left[\mathrm{J} \mathrm{mol}^{-1} \mathrm{~K}^{-1}\right], T$ is the temperature $[\mathrm{K}], n$ is the number of electrons, $\alpha$ is a transfer coefficient, $F$ is the Faraday constant $\left[\mathrm{C} \mathrm{mol}^{-1}\right], p_{i}$ is the partial pressure $[\mathrm{Pa}], i_{0}$ is the exchange current density per unit volume $\left[\mathrm{A} \mathrm{m}^{-3}\right]$, and $\gamma$ is a fitting parameter. In this study, we used the following values: $n=2.0$ and $\alpha=0.5$. The equations for the exchange current density were taken from the literature $[1,27]$. The boundary conditions are given in Eqs. (18) and (19). The electronic potentials of the current collectors were considered equal, and the overpotential of the current collector of the cathode side was determined to be $0 \mathrm{~V}$.

$$
\begin{aligned}
& \left.\frac{\partial \eta_{\mathrm{e}-}}{\partial z}=0 \text { (cathode side } z=45-50 \mathrm{~mm}\right) \\
& \frac{\partial \eta_{\mathrm{e}-}}{\partial z}=0(\text { anode side } z=10-40 \mathrm{~mm})
\end{aligned}
$$

\subsection{Heat Transport}

Heat conduction in the electrolyte and the microporous electrodes was taken into account and was determined using the following expressions:

$$
\begin{aligned}
& 0=\nabla \cdot\left(k^{\mathrm{eff}} \nabla T\right)+S_{\mathrm{T}} \\
& k^{\mathrm{eff}}=\left(1-\varepsilon_{\mathrm{p}}\right) k^{\circ}
\end{aligned}
$$

where $k^{\text {eff }}$ is the effective heat conductivity $\left[\mathrm{W} \mathrm{m}^{-1} \mathrm{~K}^{-1}\right.$ ] and $S_{\mathrm{T}}$ is an internal heat generation term $\left[\mathrm{W} \mathrm{m}{ }^{-3}\right]$. Heat convection in the channel was taken into account and was calculated using an upwind scheme. The flow in the channel was assumed to be one-dimensional and laminar in the z-direction. The heat convection in the channel was determined using the following expression:

$$
\rho C_{\mathrm{p}} w \frac{\partial T_{\mathrm{ch}}}{\partial z}=-q_{\mathrm{c}}
$$

where $\rho$ is the density $\left[\mathrm{mol} \mathrm{m}^{-3}\right], C_{\mathrm{p}}$ is the specific heat $\left[\mathrm{J} \mathrm{mol}^{-1} \mathrm{~K}^{-1}\right], w$ is the velocity in the $z$-direction $\left[\mathrm{m} \mathrm{s}^{-1}\right]$, and $q_{\mathrm{c}}$ is heat flux corresponding to heat transfer $\left[\mathrm{Wm}^{-}{ }^{2}\right.$. The subscript ch indicates the gas flow channel. $S_{\mathrm{T}}$ was determined using the following expression: 


$$
S_{\mathrm{T}}=-\frac{T \Delta S}{n F} i_{\mathrm{v}}+\eta_{\mathrm{r}} i_{\mathrm{v}}+\frac{i_{\mathrm{e}-}^{2}}{\sigma_{\mathrm{e}-}^{\mathrm{eff}}}+\frac{i_{\mathrm{ion}}^{2}}{\sigma_{\mathrm{ion}}^{\text {eff }}}+q_{\mathrm{c}}+q_{\mathrm{r}}
$$

where $i_{\mathrm{e}-}$ is the electronic current density $\left[\mathrm{A} \mathrm{m}^{-2}\right], i_{\text {ion }}$ is the ionic current density $\left[\mathrm{A} \mathrm{m}^{-2}\right], q_{\mathrm{r}}$ is the heat flux from the thermal radiation at the surfaces of the electrodes $\left[\mathrm{A} \mathrm{m}^{-2}\right]$, and $\Delta S$ is the entropy change $\left[\mathrm{J} \mathrm{mol}^{-1} \mathrm{~K}^{-1}\right] . T h e$ $\Delta S$ values for the cathode and anode were taken from the literature [23-24]. The heat flux, $q_{\mathrm{c}}\left[\mathrm{W} \mathrm{m}^{-2}\right]$, attributable to the heat transfer phenomenon at each electrode/channel surface, was determined as follows:

$$
q_{\mathrm{c}}=h_{\mathrm{T}}\left(T_{\mathrm{e}}-T_{\mathrm{ch}}\right)
$$

where $h_{\mathrm{T}}$ is the heat transfer coefficient $\left[\mathrm{W} \mathrm{m} \mathrm{m}^{-2} \mathrm{~K}^{-1}\right.$. The subscript e indicates the electrode surface. The thermal radiation outside the tube was also considered. The heat transfer coefficients were taken from the literature [26]. The heat flux of the thermal radiation, $q_{\mathrm{r}},\left[\mathrm{W} \mathrm{m}^{-2}\right]$ was determined as follows

$$
q_{\mathrm{r} \text { outside }}=\sigma_{\mathrm{SB}} \varepsilon_{\mathrm{e}}\left(T_{\mathrm{e}}^{4}-T_{\mathrm{w}}^{4}\right)
$$

where $\sigma_{\mathrm{SB}}$ is the Stefan-Boltzmann constant $\left[\mathrm{W} \mathrm{m}^{-2} \mathrm{~K}^{-4}\right]$ and $\varepsilon$ is the emissivity. The subscript $w$ refers to the wall, and $T_{\mathrm{w}}$ is the operating temperature. The thermal radiation inside the tube was determined as follows:

$$
q_{\mathrm{r} l}=\frac{\sum_{\mathrm{m}}\left[\pi \sigma _ { \mathrm { SB } } T _ { m } ^ { 4 } \left[1-\frac{\left|z_{m}-z_{l}\right|\left[\left(z_{m}-z_{l}\right)^{2}+6\left(\frac{d}{2}\right)\right]}{\left.\left.\left[\left(z_{m}-z_{l}\right)^{2}+4\left(\frac{d}{2}\right)^{2}\right]^{\frac{2}{3}}\right] \delta z_{m} \delta z_{l}\right]}\right.\right.}{\delta \mathrm{A}_{l}}+q_{\text {side } l}-\sigma_{\mathrm{SB}} T_{l}^{4}
$$

where $q_{r \text { inside }}$ is the heat flux through the surface of the cathode $\left[\mathrm{W} \mathrm{m}{ }^{-2}\right], \mathrm{q}_{\text {side }}$ is heat flux from the side of the tube $\left[\mathrm{W} / \mathrm{m}^{-2}\right], d$ is the internal diameter of the microtubular SOEC $[\mathrm{m}], \mathrm{z}$ is the position along the $\mathrm{z}$-direction [m], and $\delta z$ is the differential length of the control volume [m]. The subscripts $\mathrm{m}$ and 1 denote the position of the cell. Here, the emissivity of the microporous cathode surface was treated as being similar to that of a black body, in order to reduce the calculation load. Other details of the radiation inside the tube have been published previously [25]. 
The boundary conditions were set such that the gas outlet end of the SOEC (at $z=50 \mathrm{~mm}$ ) had the Neumann boundary condition and the gas inlet end of the cell (at $\mathrm{z}=0 \mathrm{~mm}$ ) had the isothermal condition. The casing wall and the cathode gas flow also had the isothermal condition.

\subsection{Mass Transport}

The mass balance in a microporous electrode can be calculated on the basis of the phenomenon of gas diffusion:

$$
0=\nabla \cdot\left(D_{i}^{\mathrm{eff}} \nabla C_{i}\right)+S_{C_{i}}
$$

where $D_{i}^{\text {eff }}$ is the effective gas diffusivity $\left[\mathrm{m}^{2} \mathrm{~s}^{-1}\right], C_{i}$ is the concentration of the chemical species $i$ [mol $\left.\mathrm{m}^{-3}\right]$, and $S_{C_{i}}\left[\mathrm{~mol} \mathrm{~m}^{-3}\right]$ is a gas generation term. $D_{i}^{\text {eff }}$ was calculated using the following equations:

$$
\begin{aligned}
& \frac{1}{D_{i}}=\frac{1}{D_{\mathrm{bulk}, i}}+\frac{1}{D_{\mathrm{knudsen}, i}} \\
& D_{i}^{\text {eff }}=\varepsilon_{\mathrm{p}}^{1.5} D_{i}
\end{aligned}
$$

The molecular diffusion coefficient, $D_{i}$, of the species $i$ was calculated using the bulk diffusion coefficient, $D_{\text {bulk }, i}$, and the Knudsen diffusion coefficient, $D_{\text {knudsen, } i} \cdot[16,19]$. Here, the diameter of the pores of the cathode was assumed to be $4 \mu \mathrm{m}$. To ensure mass balance in the channel, mass convection was taken into account.

$$
w \frac{\partial C_{e i}}{\partial z}=S_{\mathrm{C}_{\mathrm{i}}}
$$

The chemical species generated by the electrolysis reaction were determined as follows:

$$
\begin{aligned}
& S_{\mathrm{C}_{\mathrm{H}_{2}}}=\frac{i_{\mathrm{v}}}{\mathrm{n} F} \\
& S_{\mathrm{C}_{\mathrm{H}_{2} \mathrm{O}}}=-\frac{i_{\mathrm{v}}}{\mathrm{n} F}
\end{aligned}
$$

The mass transfer at the cathode electrode/channel surface was taken into account using the following equation: 


$$
N_{i}=h_{\mathrm{C}}\left(C_{\mathrm{e}_{i}}-C_{\mathrm{ch}_{i}}\right)
$$

where $h_{\mathrm{C}}$ is the mass transfer coefficient $\left[\mathrm{m} \mathrm{s}^{-1}\right]$, and $N_{i}$ is the mass flux of the chemical species $i\left[\mathrm{~mol} \mathrm{~m}^{-2} \mathrm{~s}^{-1}\right]$. In this study, the changes in the gas concentrations at the anode and the channel were ignored because these changes are negligibly small compared to those at the cathode side.

\subsection{Calculation Conditions}

In this study, it was assumed that the flow directions of the gas flow and the electronic current were different and that the gases and the electronic current were supplied from $z=0 \mathrm{~mm}$ and $z=50 \mathrm{~mm}$, respectively. This condition was chosen to separate the effects of the flow of the gases and that of the current on the reactive current distributions. The hydrogen supply rate was $40 \mathrm{sccm}$, that for steam was $40 \mathrm{sccm}$, and that for air was $50 \mathrm{sccm}$. The operational temperatures were $973 \mathrm{~K}, 1023 \mathrm{~K}, 1073 \mathrm{~K}$ and $1123 \mathrm{~K}$. These conditions and the others are listed in Table 3.

Table 3 Conditions used for the calculations

\begin{tabular}{lcr}
\hline Parameter & Value & Unit \\
\hline SOEC operating temperature & $973,1023,1073$ and1123 & {$[\mathrm{K}]$} \\
$\gamma_{\mathrm{c}}$ & $5.426 \times 10^{9}$ & {$\left[\mathrm{~A} \mathrm{~m}^{-3} \mathrm{~K}^{-1}\right]$} \\
$\gamma_{\mathrm{a}}$ & $1.583 \times 10^{10}$ & {$\left[\mathrm{~A} \mathrm{~m}^{-3} \mathrm{~K}^{-1}\right]$} \\
$\mathrm{H}_{2}$ flow rate (based on $298.15 \mathrm{~K}$ and $\left.0.1 \mathrm{MPa}\right)$ & 40 & {$\left[\mathrm{mLmin}^{-1}\right]$} \\
$\mathrm{H}_{2} \mathrm{O}$ flow rate (based on $298.15 \mathrm{~K}$ and $\left.0.1 \mathrm{MPa}\right)$ & 40 & {$\left[\mathrm{mLmin}^{-1}\right]$} \\
Air flow rate (based on $298.15 \mathrm{~K}$ and $0.1 \mathrm{MPa})$ & 50 & {$\left[\mathrm{mLmin}^{-1}\right]$} \\
Heat transfer coefficient of cathode $\left(\mathrm{H}_{2} / \mathrm{H}_{2} \mathrm{O}\right.$ side) & 500 & {$\left[\mathrm{Wm}^{-2} \mathrm{~K}^{-1}\right]$} \\
Heat transfer coefficient of anode $($ air side) & 2 & {$\left[\mathrm{Wm}^{-2} \mathrm{~K}^{-1}\right]$} \\
Cathode activation energy $\Delta \mathrm{E}_{\mathrm{c}}[1,27]$ & $120 \times 10^{5}$ & {$\left[\mathrm{~J} \mathrm{~mol}^{-1} \mathrm{~K}^{-1}\right]$} \\
Anode activation energy $\Delta \mathrm{E}_{\mathrm{c}}[27]$ & $130 \times 10^{5}$ & {$\left[\mathrm{~J} \mathrm{~mol}^{-1} \mathrm{~K}^{-1}\right]$} \\
\hline
\end{tabular}

\subsection{Experimental}

The potentials and temperatures in the microtubular SOEC were measured under the same conditions as those used for the calculations, however, the operating temperature was only $1123 \mathrm{~K}$. The voltage measurements in the 
microtubular SOEC were performed using a previously described method [20-22]; however, a number of measurement terminals were added. Fig. 3 shows a schematic of the measurement configuration. Two electrolysis voltages, $E_{1}$ and $E_{2}$, were measured, and the changes in the temperature at three points in the SOEC, namely, $\Delta T_{1}, \Delta T_{2}$ and $\Delta T_{3}$,were determined using K-type thermocouples. The thermocouples were electrically insulated with a coating of Ceramabond ${ }^{\mathrm{TM}} 552$ (Aremco Products Inc., US). Impedance-based temperature measurements have been performed previously [16]. This temperature measurement method exploits the relationship between the ohmic resistance of the electrode and the temperature and can be used to measure the internal temperature of SOECs. However, the method is unsuitable for making measurements at local points in a cell, because it can only measure the average value for the cell. Therefore, the measurements were made using thermocouples.

The voltages, $E_{1}$ and $E_{2}$, and the changes in the temperature, $\Delta T_{1}, \Delta T_{2}$ and $\Delta T_{3}$,were measured under constant potential control over a period of $1 \mathrm{~h}$. A data logger (NR-1000, Keyence, Japan) was used to measure the change in the voltage $E_{1}$ and that in the temperature, $\Delta T$. An electrochemical interface (IS 1287, Solartron, UK) was used to measure the change in the voltage $E_{2}$ and to apply the electron current. The gases were sealed in using Ceramabond ${ }^{\mathrm{TM}} 552$ and a glass seal.

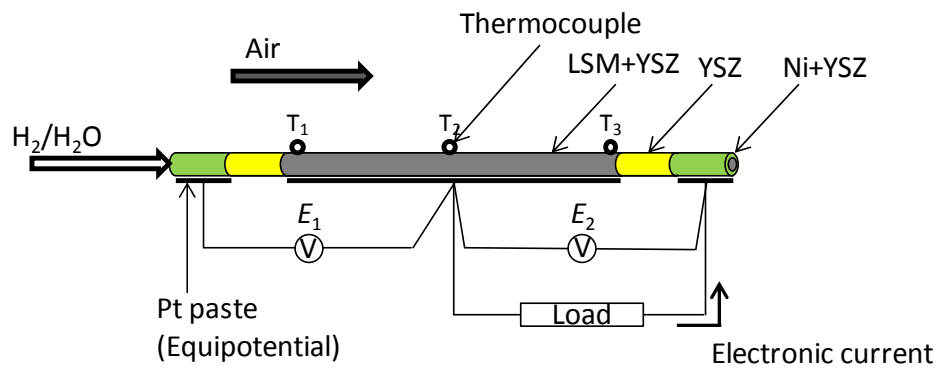

(a)

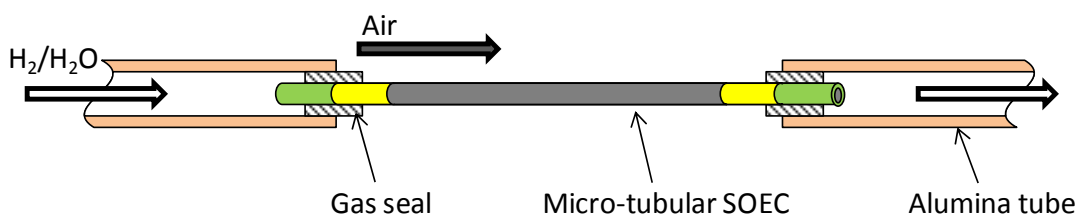

(b)

Fig. 3. Schematic of the experimental configuration: (a) locations of the thermocouples and the sections at which the voltage measurements were made in the microtubular SOEC and (b) channels for the source gases. 


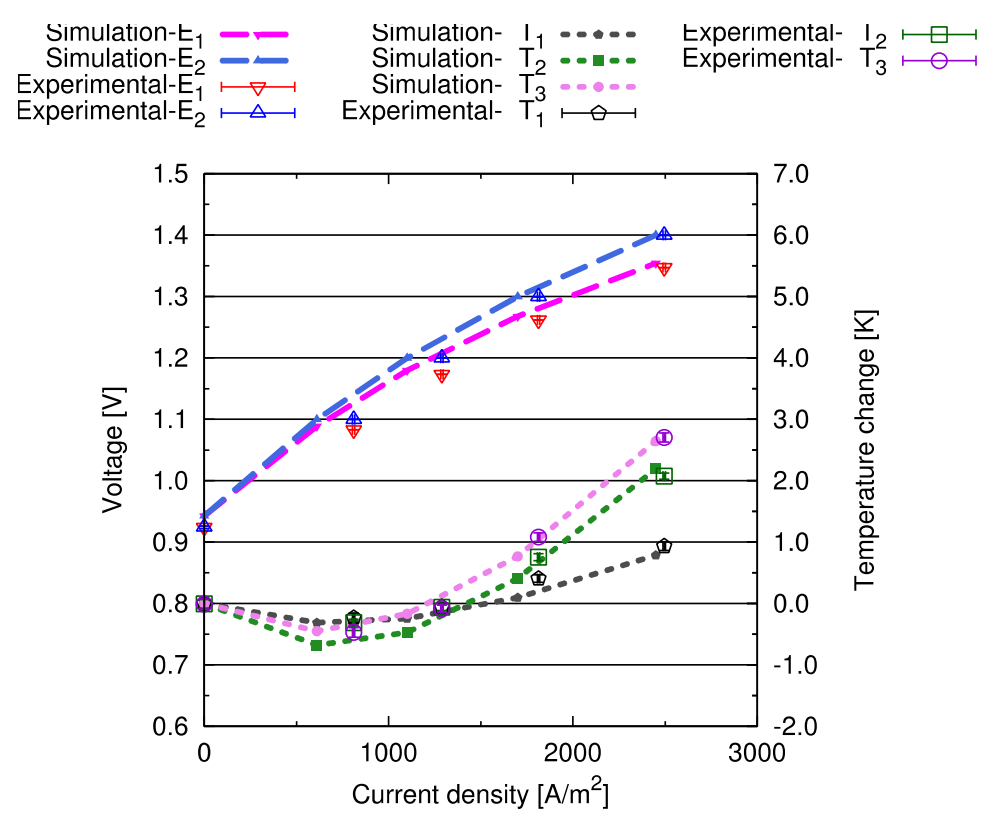

Fig. 4. Voltages and $\Delta T$ characteristics as functions of the average current density at the operating temperature of $1123 \mathrm{~K}$. Here, $\Delta T$ represents the change in the temperature with respect to the open circuit.

\section{Results and discussion}

\subsection{Comparison of experimental and numerical results}

\subsubsection{Average current density-voltage characteristics}

Fig. 4 shows the measured and calculated $i-V$ curves at $1123 \mathrm{~K}$ for a $\mathrm{H}_{2} \mathrm{O} / \mathrm{H}_{2}$ ratio of 50:50. Here, the current density is positive in the electrolysis mode and negative in the fuel cell mode. The potential $E_{2}$ of the current loading side was larger than the potential $E_{1}$ in the electrolysis mode. This phenomenon was also observed in the numerical results, because the numerical model took into account the electronic resistance along the length direction (z-direction) of the microtubular SOEC. As shown in Fig. 4, the calculated $i-V$ curves were in good agreement with the measured results. In particular, the differences between the E2 and E1 values were very small. This difference was strongly affected by the electronic tortuosity and was determined experimentally using the microtubular SOEC. The tortuosity was measured by the four-terminal method using the current collectors on both ends of the Ni+YSZ electrode, as shown in Fig 3(a). Here, $E_{1}$ and $E_{2}$ were determined numerically as follows:

$$
\begin{aligned}
& E_{1}=\eta_{\mathrm{e}^{-} \text {anode surface }}+\left(\phi_{e-a}^{0}-\phi_{\mathrm{e}-c}^{0}\right) \\
& E_{2}=\eta_{\mathrm{e}-\text { anode surface }}-\eta_{e-c z=0, r=2.0 \times 10^{-4} m}+\left(\phi_{e-a}^{0}-\phi_{e-c}^{0}\right) .
\end{aligned}
$$

3.1.2 Average current density-temperature characteristics 
The measured and calculated $i-\Delta T$ curves are also shown in Fig. 4, along with the $i-V$ curves. $\Delta T$ refers to the change in the temperature from that of the open circuit. The calculated temperatures correspond to the locations at which the measurements were made experimentally. The positions corresponding to $\Delta T_{1}, \Delta T_{2}$ and $\Delta T_{3}$ were $z=11$ $\mathrm{mm}, \mathrm{z}=25 \mathrm{~mm}$, and $\mathrm{z}=39 \mathrm{~mm}$, respectively. As shown in Fig. 4, the numerically determined changes in the temperature were in good agreement with the measured results; this was determined from the results of $\mathrm{i}-\mathrm{V}$ curve fitting. The measured $\Delta T$ values decreased until $1.1 \mathrm{~V}$ and then increased. For open circuit voltage (OCV-1.2 V, all the $\Delta T$ values were lower than $0 \mathrm{~K}$. This decrease in the temperature can be explained on the basis of the heat consumption resulting from the entropy change. For voltages greater than $1.3 \mathrm{~V}$, the changes in the temperature were higher than those for the $\mathrm{OCV}$, because the amount of heat generated by overpotentials became larger than the amount of heat consumed.

\subsection{Reactive current distributions}

The local current per unit volume $\left[\mathrm{A} \mathrm{m}^{-3}\right]$ is shown in Fig. 5(a)-(d) in the form of a color map for each potential. The position relationship for the components of the SOEC is shown in Fig. 5(e). In addition, the electrochemical reaction thickness as shown in fig. 5 was summarized in table 4 . The electrochemical reaction thickness was shown as the percentage of the total electrochemical reaction for the $\mathrm{Ni}+$ YSZ electrode in table 4. Finally, the local current density distributions [A m ${ }^{-2}$ ] are shown in Fig. 6(a). Here, the active area ranged from $z=10.0$ to $40.0 \mathrm{~mm}$. For all the conditions, the local current density increased with $z$ till the end of the reactive area (i.e., till $z=40.0$ $\mathrm{mm}$ ). The local current density distributions caused by the difference in the electron potentials of the LSM + YSZ and Ni + YSZ electrodes are shown in Fig. 6(b). This difference in the electron potentials includes the reactive overpotential and the ion resistive overpotential of the electrolyte for each z-position. The shapes of the current density and electron potential difference (overpotential) distributions were similar, as shown in Fig. 6(a), because the $i-V$ curves were almost linear. The electron potential on the $\mathrm{Ni}+\mathrm{YSZ}$ electrode surface decreasedwith $z$ till $z=$ $45.0 \mathrm{~mm}$, as shown in Fig. 6(c). The position corresponding to $\mathrm{z}=45.0 \mathrm{~mm}$ was the edge of the current collector. It was also affected by the current-collecting position, which caused the increase in the electron current density along the z-direction. For example, the electron current density along the $\mathrm{z}$-direction was greater than $4.0 \times 10^{5} \mathrm{~A} \mathrm{~m}^{-2}$ at 1.4 V, as shown in Fig. 6(d). The electron current density along the $z$-direction increased with $\mathrm{z}$ until $\mathrm{z}=40.0 \mathrm{~mm}$, owing to the electrolysis reaction, and was uniform in the nonactive area, that is, between $z=40$ and $50 \mathrm{~mm}$. 
Table 4 The electrochemical reaction thickness for the Ni+YSZ electrode

\begin{tabular}{c|cccc}
\hline \multirow{2}{*}{$\begin{array}{c}\text { Percentage of the total electrochemical } \\
\text { reaction for the Ni + YSZ electrode }\end{array}$} & \multicolumn{4}{|c}{ The thickness from the Ni+YSZ/ YSZ surface $[\mu \mathrm{m}]$} \\
\cline { 2 - 4 } & $1.1 \mathrm{~V}$ & $1.2 \mathrm{~V}$ & $1.3 \mathrm{~V}$ & $1.4 \mathrm{~V}$ \\
\hline $75 \%$ & 44 & 42 & 40 & 37 \\
$80 \%$ & 51 & 50 & 47 & 44 \\
$85 \%$ & 61 & 59 & 57 & 54 \\
$90 \%$ & 74 & 73 & 70 & 67 \\
\hline
\end{tabular}

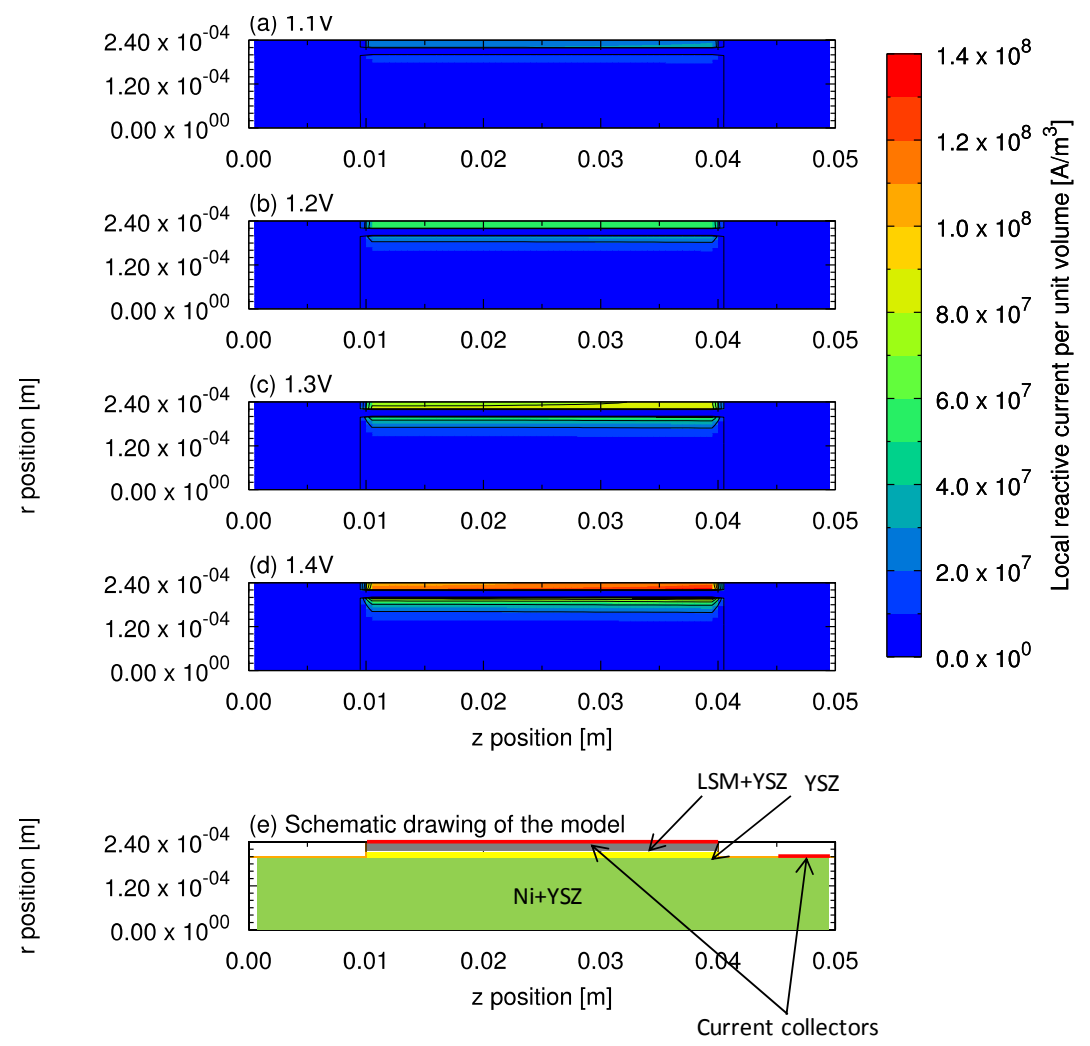

Fig. 5 Distributions of the local reactive current per unit volume in the microtubular SOEC for potentials of (a) 1.1 $\mathrm{V}$, (b) $1.2 \mathrm{~V}$, (c) $1.3 \mathrm{~V}$, and (d) $1.4 \mathrm{~V}$ at the operating temperature of $1123 \mathrm{~K}$. (e)Schematic of the two-dimensional distribution graph. 

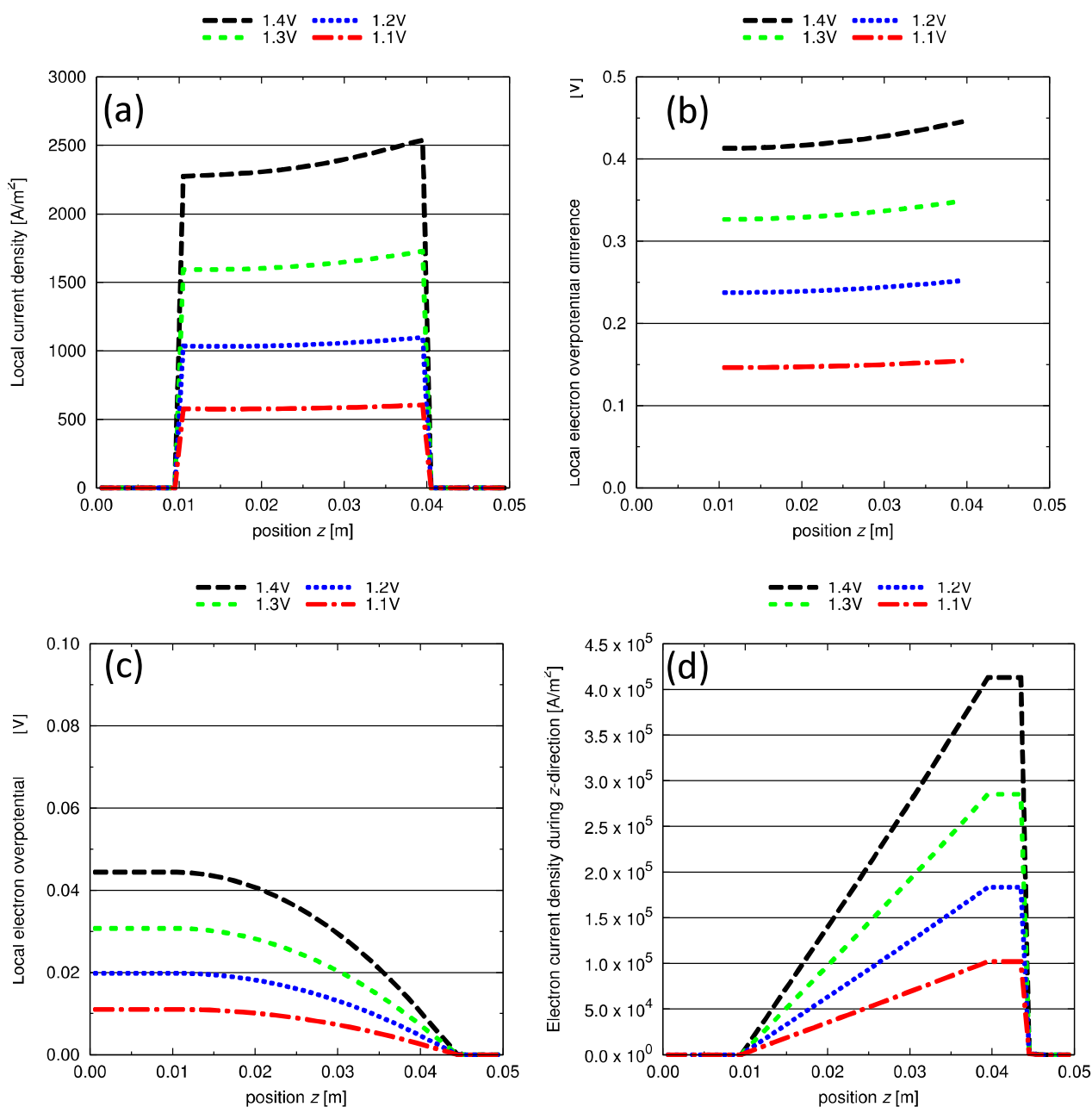

Fig. 6. (a) Local current density distributions for the potentials of $1.1 \mathrm{~V}, 1.2 \mathrm{~V}, 1.3 \mathrm{~V}$, and $1.4 \mathrm{~V}$. (b) Distributions of the electron overpotential differences between the LSM + YSZ and Ni + YSZ electrodes. (c) Distributions of the electron overpotential of the Ni + YSZ electrode. (d) Distributions of the current density in the z-direction for the potentials. These results were calculated at the operating temperature of $1123 \mathrm{~K}$.

\section{$3.3 \Delta T$ distributions}

The two-dimensional temperature distributions were determined using the numerical model. The results are shown in Fig. 7. It can be seen from the figure that the changes in the temperature along the $r$-direction was very small.

The numerical and experimental $\Delta T$ distributions at the LSM + YSZ electrode surface are shown in Fig. 8. The measured and calculated temperature changes were in good agreement. The temperature distribution for each condition was different. For example, although $\Delta T$ was larger than $0 \mathrm{~K}$ at all positions for $1.3 \mathrm{~V}$ and $1.4 \mathrm{~V}$, it was 
lower than $0 \mathrm{~K}$ in the active area for $1.2 \mathrm{~V}$ and $1.1 \mathrm{~V}$. The bulk tendency of the temperature change was determined by electrolysis voltage, and the voltage with balanced heat sources was called thermoneutral voltage[20]. In this point, the total amount of heat generation and absorption was equaled. Generally, the thermoneutral voltage hardly depends on the operation temperature and the value is bit under the $1.3 \mathrm{~V}$. As shown in fig. 8, the direction of the temperature change was changed between $1.2 \mathrm{~V}$ and $1.3 \mathrm{~V}$. This results suggested that the numerical model and measured value wereconsistent with the thermodynamical thermoneutral voltage.

On the other hand, for all the conditions, the temperature gradients were larger near the boundary point of the active/nonactive area, that is, at $z=10 \mathrm{~mm}$ and $\mathrm{z}=40 \mathrm{~mm}$. These temperature distributions are caused by the fact that there exist distributions related to the heat generated and absorbed; these were calculated using the distributions of the reactive current density, the overpotentials, and the current densities along the $z$-direction and the $r$-direction. The final heat source distributions are shown in Fig. 9. The net heat balances for $1.1 \mathrm{~V}$ and $1.2 \mathrm{~V}$ were lower than $0 \mathrm{~W} \mathrm{~m}^{-2}$ in the active area. In contrast, those for $1.3 \mathrm{~V}$ and $1.4 \mathrm{~V}$ increased until the right end of the active area $(\mathrm{z}=40 \mathrm{~mm})$ and exhibited a peak at the right end of the active area. In order to separate the heat generated and absorbed, the net heat balance $\left(q_{\text {total }}\right)$ as well as the heat source distributions owing to the ionic $\left(q_{\eta_{\text {ion }}}\right)$ and electronic $\left(q_{\eta_{\mathrm{e}-}}\right)$ resistances, the reactive overpotential $\left(q_{\mathrm{r}}\right)$, and the change in entropy $\left(q_{-T \Delta S / n}\right)$ for each condition are shown in Figs. 10(a), 10(b), 10(c), and 10(d), respectively. For $1.1 \mathrm{~V}$ and $1.2 \mathrm{~V},-q_{-T \Delta S / n}$ was larger than the sum of $q_{\eta_{r}}, q_{\eta_{\text {ion }}}$, and $q_{\eta_{\mathrm{e}}}$ in the active area. As a result, $q_{\text {total }}$ had a negative value, and $\Delta T$ was lower than $0 \mathrm{~K}$ in the active area. On the other hand, $q_{\text {total }}$ was positive in the nonactive area, that is, for $\mathrm{z}$ of $40-50$ $\mathrm{mm}$, because, in this case, heat was generated only because of the electronic resistance. Therefore, $\Delta T$ was larger than $0 \mathrm{~K}$ in the nonactive area.For $1.3 \mathrm{~V}$ and $1.4 \mathrm{~V}$, the total amounts of heat generated were larger than $-q_{-T \Delta S / n}$ in the active area. As a result, the net heat balance was attributable to the heat generated in both the active and the nonactive areas.

As mentioned above, the trends in the net heat source distributions were significantly different for each current density, and the temperature distributions were directly affected by the net heat source distributions, as shown in Figs. 8 and 9. In addition, the net heat source distributions themselves were affected by the overpotential and/or the reactive current distributions, which were determined by the current-collecting positions. 


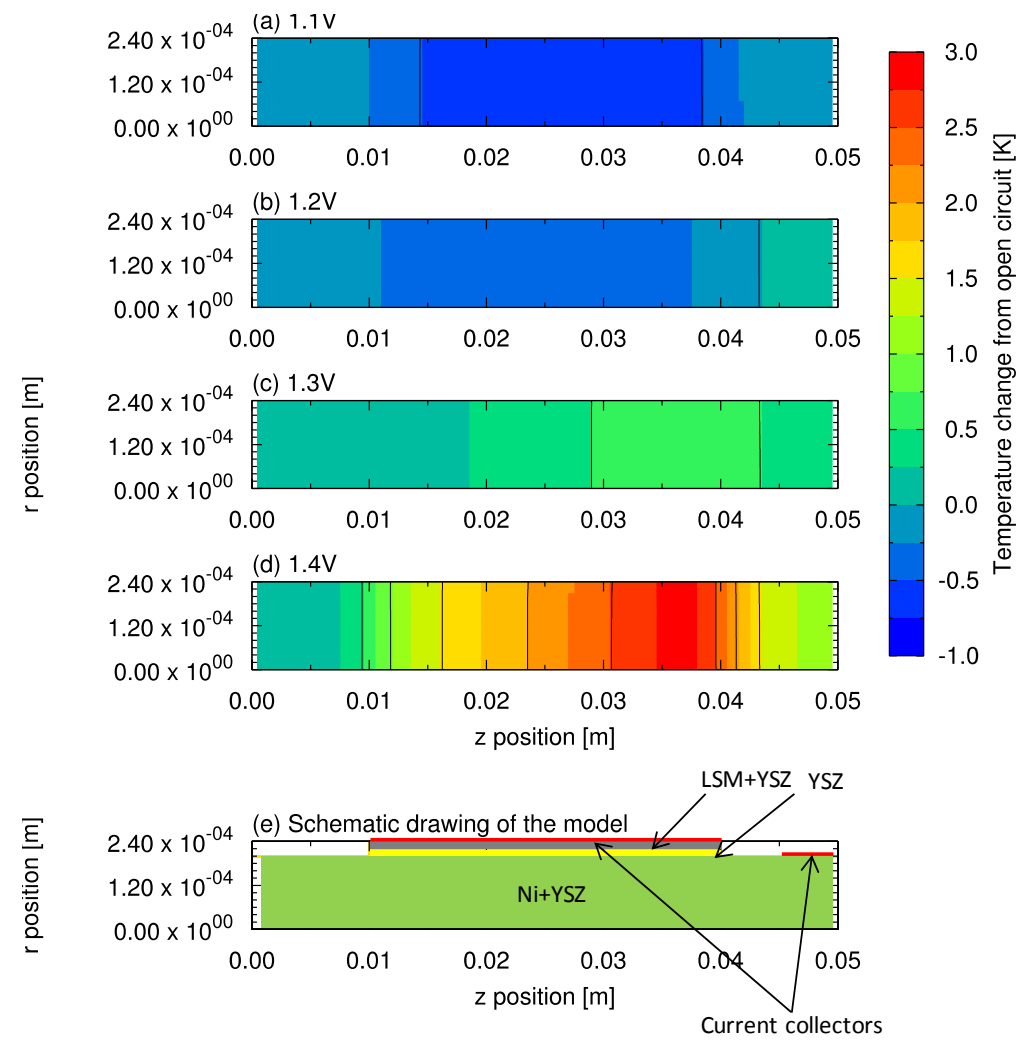

Fig. 7. Two-dimensional $\Delta T$ distributions in the microtubular SOEC for the potentials of (a) $1.1 \mathrm{~V}$, (b) $1.2 \mathrm{~V}$, (c) $1.3 \mathrm{~V}$, and (d) $1.4 \mathrm{~V}$ at the operating temperature of $1123 \mathrm{~K}$. (e) Schematic of the two-dimensional distribution graph.

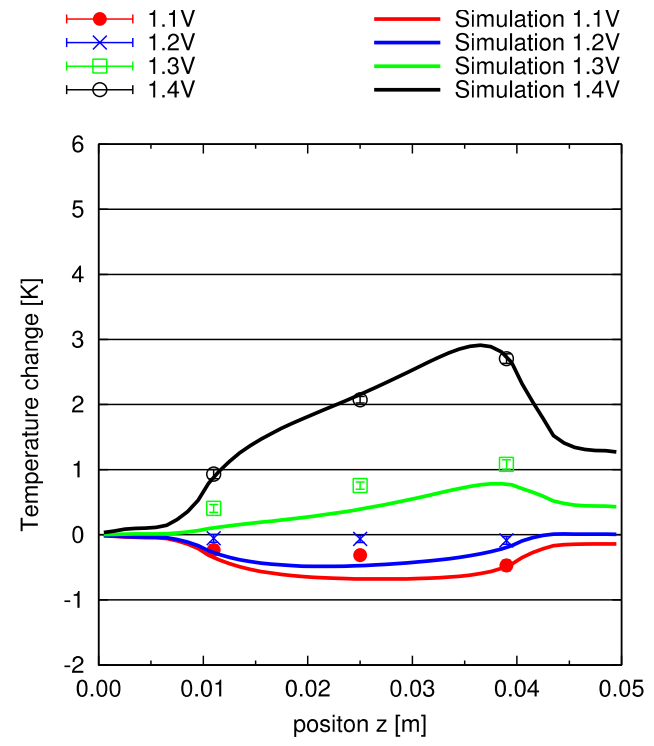


Fig. 8. Measured and numerical distributions of $\Delta T$ at the LSM + YSZ surface for the potentials at the operating temperature of $1123 \mathrm{~K}$.

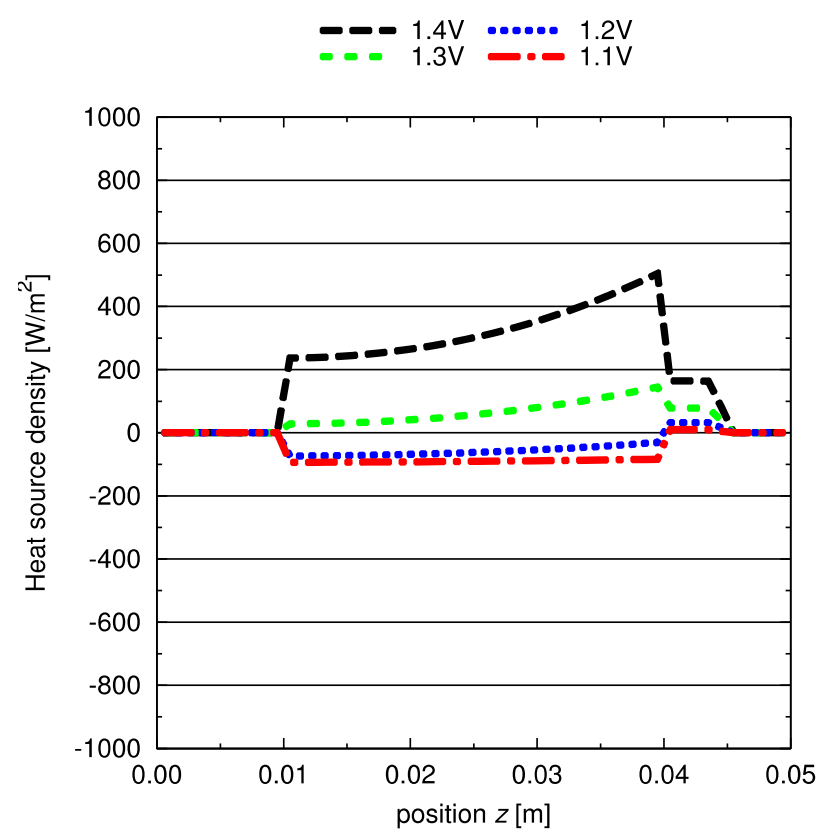

Fig. 9. Net heat source density distributions for the potentials at the operating temperature of $1123 \mathrm{~K}$. 


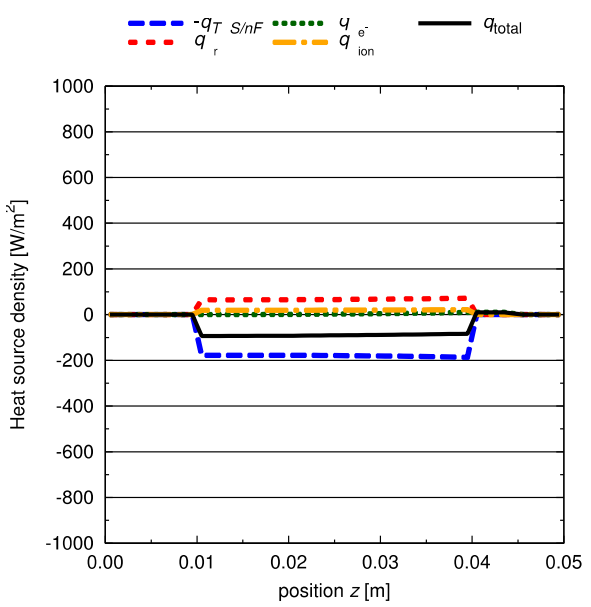

(a) $1.1 \mathrm{~V}$

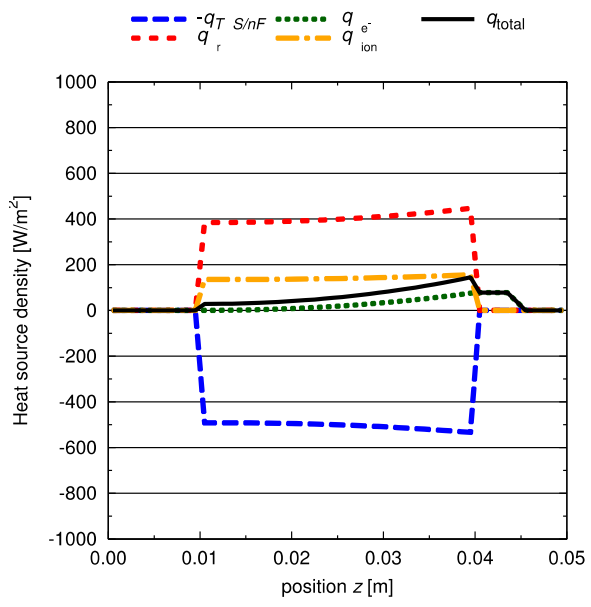

(c) $1.3 \mathrm{~V}$

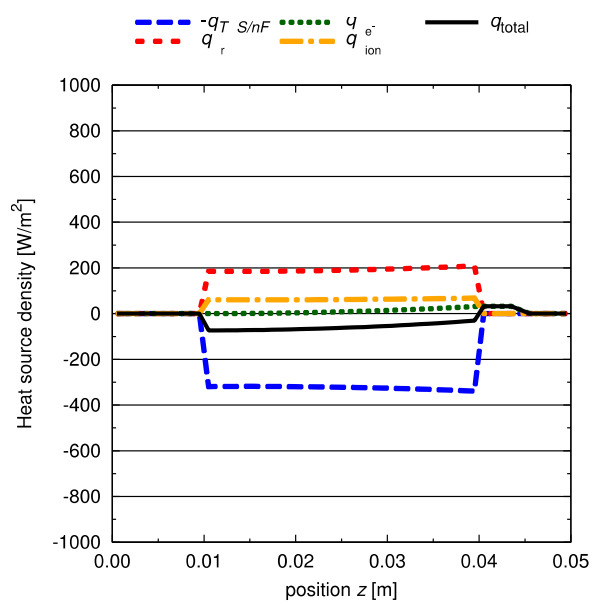

(b) $1.2 \mathrm{~V}$

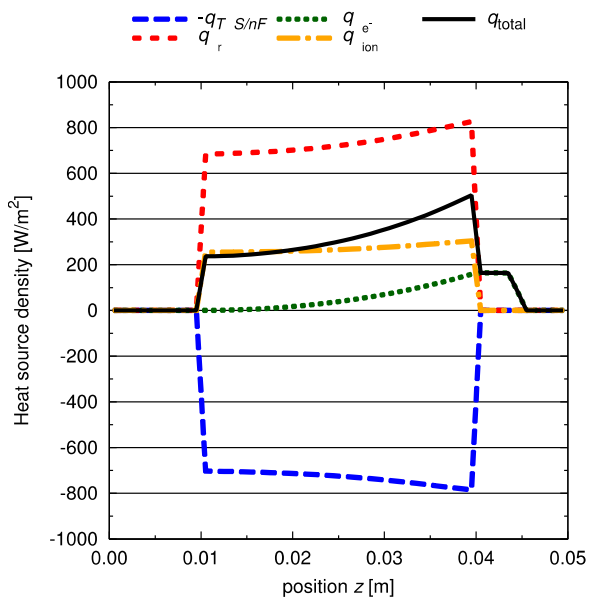

(d) $1.4 \mathrm{~V}$

Fig. 10 Heat source density distributions for the potentials of (a) $1.1 \mathrm{~V}$, (b) $1.2 \mathrm{~V}$, (c) $1.3 \mathrm{~V}$, and (d) $1.4 \mathrm{~V}$ at the operating temperature of $1123 \mathrm{~K}$.

\subsection{Comparison of the operating temperatures}

For discussing the effects of the operating temperature, the $i-V$ curvesat 3 furnace temperatures were shown in fig.

11. The decreased current densityat each voltage wereobtainedby decreasing operating temperature. The temperature changes from OCVat the cell center were also plotted in fig.11, and the temperature changesbecame smaller with decreasing operating temperature, net heat sources were also decreased by lowering the temperature with decreased current density. 
The temperature distribution at each electrolysis voltage and furnace temperature were depicted in fig. 12 . The tendency of the temperature distribution at each electrolysis voltage showed similarity for each furnace temperature, because the thermoneutral voltage was hardly changed with the operating temperature. The temperature changes of $1.4 \mathrm{~V}$ and $1.3 \mathrm{~V}$ were exothermic, and those of $1.2 \mathrm{~V}$ and $1.1 \mathrm{~V}$ were endothermic.

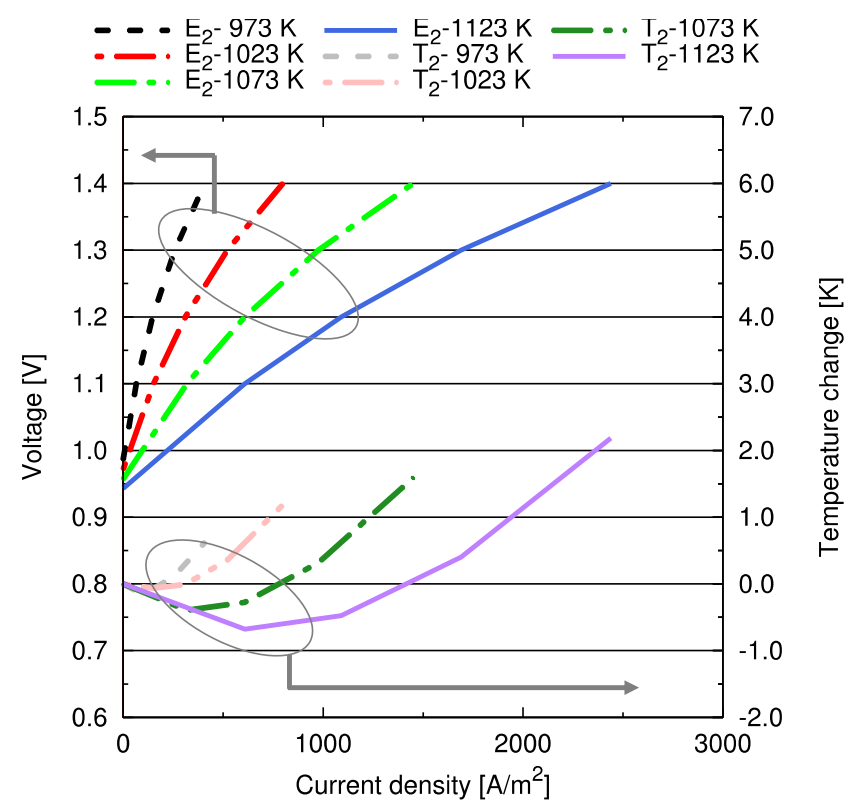

Fig. 11 Voltages and $\Delta T$ characteristics as functions of the average current density to compare the effects of the operating temperatures. Here, $\Delta T$ represents the change in the temperature with respect to the open circuit. 

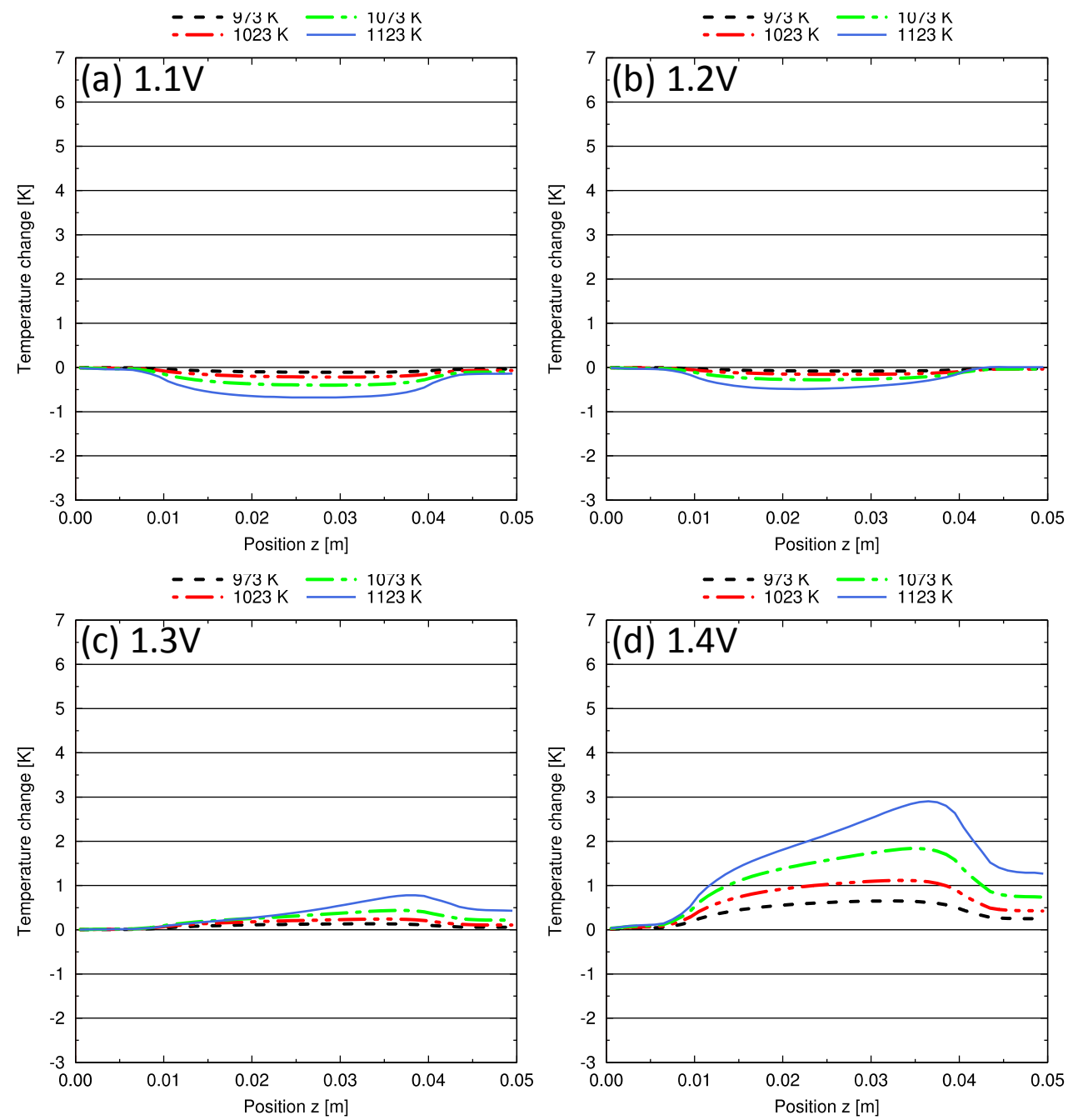

Fig. 12 Comparison of the numerical $\Delta T$ distributions at the LSM + YSZ surface from operating temperatures of $973 \mathrm{~K}$ to that of $1123 \mathrm{~K}$. the $\Delta T$ distributions for the potentials of (a) $1.1 \mathrm{~V}$, (b) $1.2 \mathrm{~V}$, (c) $1.3 \mathrm{~V}$, and (d) $1.4 \mathrm{~V}$.

\section{Conclusions}

To elucidate the temperature and reactive current distributions in microtubular SOECs, a two-dimensional tubular model that could simultaneously simulate heat, mass, and charge transport and the corresponding electrochemical reactions was developed, and temperatures at three different points of the SOEC were measured using K-type thermocouples. The calculated $i-\Delta T$ and $i-V$ characteristics were compared with those determined experimentally; the two were found to be in good agreement. For the $i-V$ characteristics, two voltages, namely, $E_{1}$ and $E_{2}$,which were the differences in the potentials of the LSM + YSZ electrode and the two ends of the Ni + YSZ electrode, were measured simultaneously. The voltage of the current-collecting side, $E_{2}$, was larger than $E_{1}$.From 
the results of the calculations, it was determined that the difference in $E_{1}$ and $E_{2}$ was caused by an overpotential distribution. In addition, this overpotential distribution also affected the reactive current and temperature distributions and was itself caused by a gradation in the electron potential in the $\mathrm{Ni}+\mathrm{YSZ}$ electrode. Furthermore, the electron potential distribution was also determined by the current-collecting position and was affected by the geometry of the microtubular SOEC. In other words, the high electronic resistance in the z-direction, which was attributable to the thin nature of the Ni + YSZ electrode, enhanced the effects of the current-collecting position. As a result, the current-collecting position strongly determined the overpotential, temperature, and reactive current distributions in the microtubular SOEC. Therefore, it is necessary to consider the temperature and reaction distributions as well as the gas diffusivity and mechanical strength when developing components for microtubular SOECs.

\section{Acknowledgements}

We would like to thank Dr. Toshiaki Yamaguchi and the members of the Inorganic Functional Materials Research Institute of the National Institute of Advanced Industrial Science and Technology (AIST) for supplying the microtubular SOEC and advising us on the experiments performed in this study.

\section{References}

[1] M. Ni, M. K. Leung and D. Y. Leung, Parametric study of solid oxide steam electrolyzer for hydrogen production,Int. J. Hydrogen Energy, 32(13) (2007), 2305-2313.

[2] M. Ni, M. K. Leung and D. Y. Leung, Energy and exergy analysis of hydrogen production by solid oxide steam electrolyzer plant, Int. J. Hydrogen Energy, 32(18) (2007), 4648-4660.

[3] T. Mutoh, T. Mizusawa, M. Mori and T. Araki, Exergy analysis by means of cycle calculation for steam electrolysis systems using solid oxide electrolysis cells,Trans. Jpn. Soc. Mech. Eng. Series C (in Japanese), 79(808) (2013), 2582-2586.

[4] M. Laguna-Bercero, S. Skinner and J. Kilner, Performance of solid oxide electrolysis cells based on scandia stabilised zirconia, J. Power Sources, 192(1) (2009), 126-131.

S. D. Ebbesen, J. Høgh, K. A. Nielsen, J. U. Nielsen and M. Mogensen, Durable SOC stacks for production of hydrogen and synthesis gas by high temperature electrolysis, Int. J. Hydrogen Energy, 36(13) (2011), 7363-7373.

[6] C. Stoots, J. O’ Brien, J. Herring, K. Condie, L. Moore-McAteer, J. J. Hartvigsen andD. Larsen, High 
temperature solid-oxide electrolyzer 2500 hour test results at the Idahonational laboratory, American Society of Chemical Engineers Annual Meeting, (2009), 8-13.

[7] J. Stephen Herring, J. E. O’Brien, C. M. Stoots, G. L. Hawkes, J. J. Hartvigsen and M. Shahnam, Progress in high-temperature electrolysis for hydrogen production using planar sofc technology, Int. J. Hydrogen Energy, 32(4) (2007), 440-450.

[8] M. Ni, 2D thermal modeling of a solid oxide electrolyzer cell (SOEC) for syngas production by $\mathrm{H}_{2} \mathrm{O} / \mathrm{CO}_{2}$ co-electrolysis, Int. J. Hydrogen Energy, 37(8) (2012), 6389-6399.

[9] J. Udagawa, P. Aguiar and N. Brandon, Hydrogen production through steam electrolysis: Model-based steady state performance of a cathode-supported intermediate temperature solid oxide electrolysis cell, J. Power Sources, 166(1) (2007), 127-136.

[10] J. Udagawa, P. Aguiar and N. Brandon, Hydrogen production through steam electrolysis: Model-based dynamic behaviour of a cathode-supported intermediate temperature solid oxide electrolysis cell, J. Power Sources, 180(1) (2008), 46-55.

[11] T. Hikosaka, Iwata, K. Onda, K. Ito and S. Nagata, System efficiency of high-temperature water electrolysis by planar solid oxide electrolysis cell, Trans. Inst. Elec. Eng. Jpn. B (in Japanese), 120(5) (2000), 694-703.

[12] S. Sohn, J. H. Nam, D. H. Jeon and C.-J. Kim, A micro/macroscale model for intermediate temperature solid oxide fuel cells with prescribed fully-developed axial velocity profiles in gas channels, Int. J. Hydrogen Energy, 35(21) (2010), 11890-11907.

[13] S. Nagata, A. Momma, T. Kato, Y. Kasuga, Numerical analysis of output characteristics of tubular SOFC with internal reformer, J. Power Sources, 101 (2001) 60-71.

[14] H. Iwai, Y. Yamamoto, M. Saito and H. Yoshida, Numerical simulation of intermediate-temperature direct-internal-reforming planar solid oxide fuel cell, Energy, 36(4) (2011), 2225-2234.

[15] M. Ni, M. K. Leung and D. Y. Leung,A modeling study on concentration overpotentials of a reversible solid oxide fuel cell, J. Power Sources, 163(1) (2006), 460-466.

[16] J.-C. Njodzefon, D. Klotz, A. Kromp, A. Weber and E. Ivers-Tiffée., Electrochemical modeling of the current-voltage characteristics of an SOFC, J. Electrochem. Soc., 160(4) (2013), F313-F323.

[17] J. Ferguson, J. Fiard and R. Herbin, Three-dimensional numerical simulation for various geometries of solid oxide fuel cells, J. Power Sources, 58(2) (1996), 109-122.

[18] W. Kiatkittipong, T. Tagawa, S. Goto, S. Assabumrungrat and P. Praserthdam, Chem. Oxygen transport through LSM/YSZ/LaAlO system for use of fuel cell type reactor, Eng. J., 106(1) (2005), 35-42.

[19] J.W. Kim, A. V Virkar, K.-Z. Fung, K. Mehta and S. C. Singhal, Polarization effects in intermediate temperature, anode-supported solid oxide fuel cells, J. Electrochem. Soc., 146(1) (1999), 69-78.

[20] Z. Wang, M. Mori and T. Araki, Int. Steam electrolysis performance of intermediate-temperature solid oxide electrolysis cell and efficiency of hydrogen production system at $300 \mathrm{Nm}^{3} \mathrm{~h}^{-1}, \mathrm{~J}$. Hydrogen Energy, 35(10) (2010), 4451-4458. 
[21] S. Hashimoto, Y. Liu, M. Mori, Y. Funahashi and Y. Fujishiro, Study of steam electrolysis using a microtubular ceramic reactor, Int. J. Hydrogen Energy, 34(3) (2009), 1159-1165.

[22] M. A. Lagnuna-Bercero, R. Campana, A. Larrea, J. A. Kilner and Y. M. Orera, Steam electrolysis using a microtubular solid oxide fuel cell, J. Electrochem. Soc., 157(6) (2010), B852-B855.

[23] E. Ahlgren and F. W. Poulsen, Thermoelectric power of YSZ, Solid State Ionics, 70/71 (1994), 528-532.

[24] H. Nakajima, T. Kitahara, Current distribution analysis of a microtubular solid oxide fuel cell with surface temperature measurements, ECS Transactions, 35(1) (2011), 1087-1096.

[25] Y. Ito, Temperature distribution of the thin-walled hollow cylinder at radiating temperature, Oyo Buturi, 26(1) (1957), 29-36 (in Japanese).

[26] R. Bird, W. E. Stewart and E. N. Lightfoot, Transport Phenomena Second Edition, John Wiely \& Sons, Inc, (2007), 422-453.

[27] R. Suwanwarangkul, E. Croiset, E. Entchev, S. Charojrochkul, M. D. Pritzker, M. W. Fowler, P. L. Douglas, S. Chewathanakup and H. Mahaudom, Experimental and modeling study of solid oxide fuel cell operating with syngas fuel, J. Power Sources, 161 (2006), 308-322. 